\title{
ELECTRON BEAM WELDING OF CENTRIFUGAL COMPRESSOR IMPELLERS
}

\author{
V.M. NESTERENKOV, L.A. KRAVCHUK and Yu.A. ARKHANGELSKY \\ E.O. Paton Electric Welding Institute, NASU \\ 11 Kazimir Malevich Str., 03680, Kiev, Ukraine. E-mail: office@paton.kiev.ua
}

\begin{abstract}
Nowadays the impellers of centrifugal machines are manufactured by vacuum brazing, arc welding and braze welding. In order to achieve a more perfect production of impellers the technology of electron beam welding of T-joints of the «disc-blade» type as-applied to impellers of centrifugal machines was developed. The investigations on the development of technology for EBW of high-alloy corrosion-resistant steel X3CrNiMo13-4 of austenitic-martensitic class were carried out to create an impeller of the centrifugal compressor with wall thickness of the covering disc of 12, 15, $20 \mathrm{~mm}$ and $6 \mathrm{~mm}$ thickness of the blade. The optimal power, time and spatial parameters of the electron beam were obtained providing the formation of high-quality welds of a slot type of the required penetration depth. To produce fillets of 2-3 mm radius the joining method between the blade and the covering disc was proposed by melting metallic inserts which were fastened on the both sides of the blade. The impeller of centrifugal compressor, welded according to the developed technology, passed static and dynamic balancing with the subsequent acceleration tests. The developed technology of EBW of impellers can be used in the structures intended for service under the vibration loads. 6 Ref., 14 Figures.
\end{abstract}

Keywords : electron beam welding, centrifugal compressor, blades, discs, high-alloy steel, T-joint, high-temperature brazing alloys, fillet, acceleration tests

EBW refers to the methods of welding using highly-concentrated power sources, allowing joining the metal of up to $300 \mathrm{~mm}$ thickness in one pass. The high levels of ductility of welded joints provide a successful application of EBW in the production of parts made of heat-hardened materials, when the postweld heat treatment is not possible.

The technological prospects of EBW give opportunity to design and create the new high-performance designs of gas-turbine engines. For example, the new challenging task of the power engineering is the manufacture of impellers of the centrifugal compressor with improved operational characteristics, as well as the improvement of reliability of the input and reverse guiding devices [1].

An impeller of the centrifugal compressor consists of the main and the covering disc with the blades located between them forming inter-blade channels. During operation of the impeller under the action of inertial forces a dust is deposited on the main disc and is pushed out to the perimeter of the impeller under the action of centrifugal forces. Considering the high speeds of impeller rotation, the movement of dust along the inter-blade channels is accompanied by a wear of the blades. To the most intensive wear the places of mating the blades with the main and the covering disc of the impellers are subjected. Therefore, to increase the life of operating impellers of centrifugal compressors it is necessary to produce mating places with radius of 2-3 mm. The development of technological process for joining the covering disc with the blades providing the mating radius of $2-3 \mathrm{~mm}$ is the aim of this work.

For manufacture of compressor impellers, steel 1.4313 (according to DIN - $\mathrm{X} 3 \mathrm{CrNiMo13-4)}$ is widely used, which refers to the corrosion-resistant steels of austenitic-martensitic class. The chemical composition of steel 1.4313 according to standard EN 10088-3 is the following: wt.\%: $\leq 0.05 \mathrm{C} ; \leq 0.7 \mathrm{Si}$; $\leq 1.5 \mathrm{Mn} ; 12-14 \mathrm{Cr} ; 0.3-0.7 \mathrm{Mo} ; \geq 0.02 \mathrm{~N} ; \leq 0.04 \mathrm{P}$; $\leq 0.015 \mathrm{~S} ; 3.5-4.5 \mathrm{Ni}$. The mechanical properties of steel are the following: $\sigma_{0.2} \geq 800 \mathrm{MPa} ; \sigma_{\mathrm{t}} \geq 900 \mathrm{MPa}$; $\delta \geq 12 \% ; \psi \geq 40 \% ; K C V \geq 70 \mathrm{~J} / \mathrm{cm}^{2}$.

The investigation of characteristics of EBW of steel X3CrNiMo13-4 in vacuum was carried out in installation UL-209M with the computer control of all the parameters and systems. Installation UL-209M is equipped with power complex ELA-60/60 and EB gun moved inside the vacuum chamber along linear coordinates $X, Y, Z$, and also rotated around axis $Y-Y$ along coordinate $Q G$ at angle of $0-90^{\circ}$. Additional$1 y$, the installation is modified with a rotator having a horizontal rotation axis (Figure 1).

The vacuum chamber of the installation with inner dimensions of $3850 \times 2500 \times 2500 \mathrm{~mm}$ and volume of $24 \mathrm{~m}^{3}$ is pumped out in the automatic control mode to operating vacuum of $2.66 \cdot 10^{-2} \mathrm{~Pa}\left(2 \cdot 10^{-4} \mathrm{Hg} \mathrm{mm}\right)$ for $25 \mathrm{~min}$. 


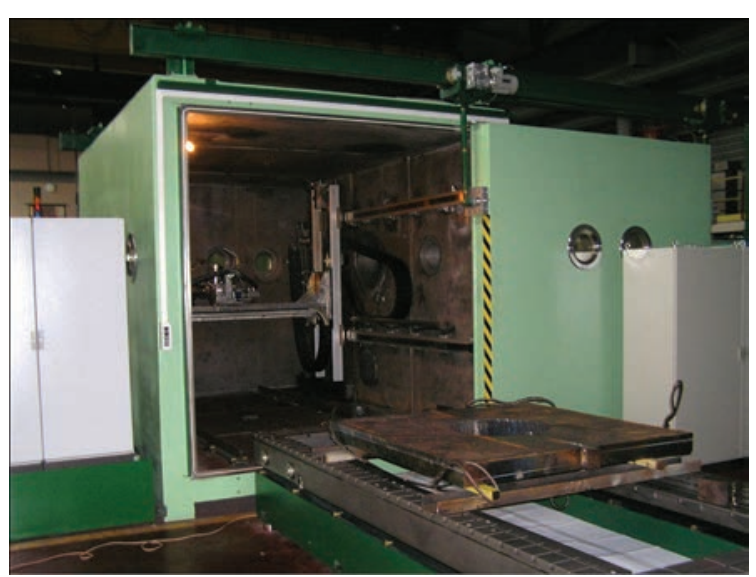

Figure 1. General view of EB installation UL-209M

During accelerating voltage $U_{\text {acc }}=60 \mathrm{kV}$ the EB gun with of tungsten cathode together with power complex ELA-60/60 provides the range of EB current of 0-500 mA and the formation of technological beam scans in the process of EBW (circle, ellipse, dash line, triangle) with amplitude of $0-4 \mathrm{~mm}$. The positioning accuracy of the EB gun along the coordinates was not less than $0.1 \mathrm{~mm}$. The image of welding place in the secondary emission electrons and also centering the electron beam with the butt at accuracy of not less than $0.1 \mathrm{~mm}$ was performed using RASTR- 6 system.

During practicing the technology of EBW of steel X3CrNiMo13-4 the control of electron beam focusing was carried out according to the definition of beam trace image on the specimen surface displayed on the monitor of RASTR-6 system and in parallel according to the brightness of illumination of the circular beam scan of diameter $d_{\mathrm{c}}=5 \mathrm{~mm}$ with $I_{\mathrm{b}} \sim 10 \mathrm{~mA}$ on the copper plate. The discrepancy of the compared focusing current values at operating distance from the

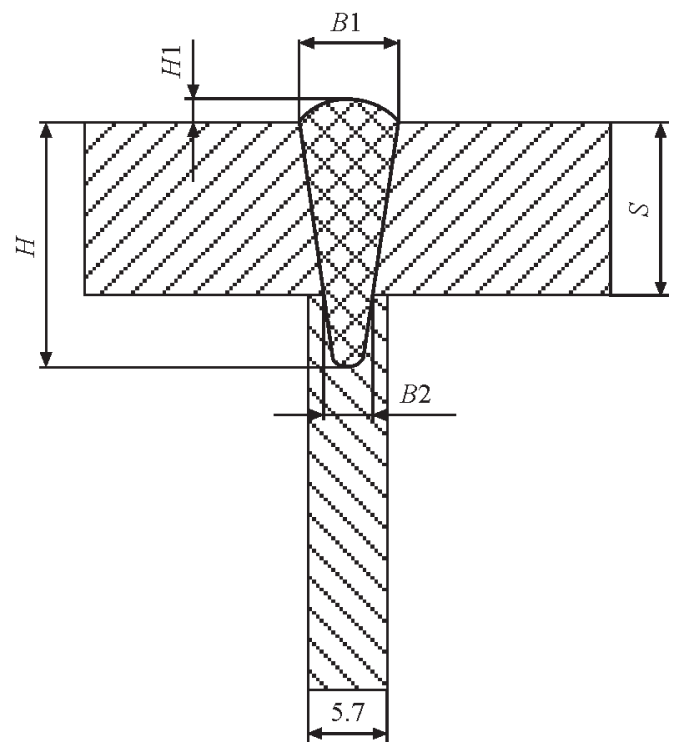

Figure 2. Scheme of T-joint of «disc-blade» type: $H$ - weld depth; H1 - height of weld reinforcement; $S$ - thickness of covering disc; $B 1$ and $B 2$ - weld width in its upper part and in the contact plane of covering disc with blade, respectively gun cut to the plates to be welded in the range of $L_{\text {op }}=$ $=150-250 \mathrm{~mm}$ amounted to $\pm 1 \mathrm{~mA}$ at the level of $I_{\mathrm{f}}=$ $=620-650 \mathrm{~mA}$, that is quite acceptable for practical application.

At the first stage of investigations the technology for joining the covering disc with the blade was practiced using slot welds. Taking into account the design features of the impeller, the most optimal EBW parameters were selected providing the formation of welds of 16, 19 and $25 \mathrm{~mm}$ depth. The system of simultaneous movement of the gun of installation UL209M along coordinates $X-X, Y-Y$ and $Z-Z$ together with RASTR-6 system provides positioning of the electron beam along the surface of the covering disc at accuracy of $0.1 \mathrm{~mm}$. At the same time, on the produced T-joints the weld root is located exactly in the center of the blade (Figure 2).

Before the assembly of T-joints the surfaces of the blade and the disc were degreased with a solvent or alcohol. The assembly for EBW was carried out applying spot tacks using argon arc welding along the ends of the billets at $l_{\mathrm{op}}=150 \mathrm{~mm}$ and $I_{\mathrm{f}}=665 \mathrm{~mA}$.

At $12 \mathrm{~mm}$ thickness of the covering disc the required weld formation was achieved at the following mode: $I_{\mathrm{w}}=110 \mathrm{~mA}, I_{\mathrm{f}}=658 \mathrm{~mA}, v_{\mathrm{w}}=4.2 \mathrm{~mm} / \mathrm{s}$, amplitude of the transverse scanning $A=4 \mathrm{~mm}$. The obtained weld geometry was the following: $B 1=$ $=7.5 \mathrm{~mm}, B 2=3.5 \mathrm{~mm}$ with penetration depth $H=$ $=16 \mathrm{~mm}$ and height of face bead $H 1=1.7 \mathrm{~mm}$.

With the growth in thickness of the covering disc to $15 \mathrm{~mm}$ the EBW parameters were changed to the following values: $I_{\mathrm{w}}=120 \mathrm{~mA}, I_{\mathrm{f}}=655 \mathrm{~mA}, v_{\mathrm{w}}=3.5 \mathrm{~mm} / \mathrm{s}$ at $A=4 \mathrm{~mm}$. Under such modes a good formation of the face weld with $B 1=8 \mathrm{~mm}, B 2=3.7 \mathrm{~mm}, H=19.5 \mathrm{~mm}$ and $H 1=1.7 \mathrm{~mm}$ was obtained.

For welding of T-joints of the covering discs of $20 \mathrm{~mm}$ thickness the following EBW parameters were used: $I_{\mathrm{w}}=130 \mathrm{~mA}, I_{\mathrm{f}}=652 \mathrm{~mA}, v_{\mathrm{w}}=2.8 \mathrm{~mm} / \mathrm{s}$, $A=4 \mathrm{~mm}$, and good formation of face bead with $B 1=9.0 \mathrm{~mm}, B 2=3.5 \mathrm{~mm}, H=24.5 \mathrm{~mm}$ and $H 1=$ $=1.9 \mathrm{~mm}$ was obtained.

The general view of the EB-welded upper beads of the covering discs of 12, 15 and $20 \mathrm{~mm}$ thickness is shown in Figure 3, and their cross-section - in Figure 4.

The carried out quality control of welded joints showed the absence of any defects in them.

To produce fillet of $2-3 \mathrm{~mm}$ radius between the blade and the covering disc the possibility of applying brazing alloys and additional metal inserts in the mating places was investigated. Such technological processes are known and their results are published in the literature [2-6].

In the work the brazing alloys were used, widely applied in the industry of Ukraine. First of all, they in- 


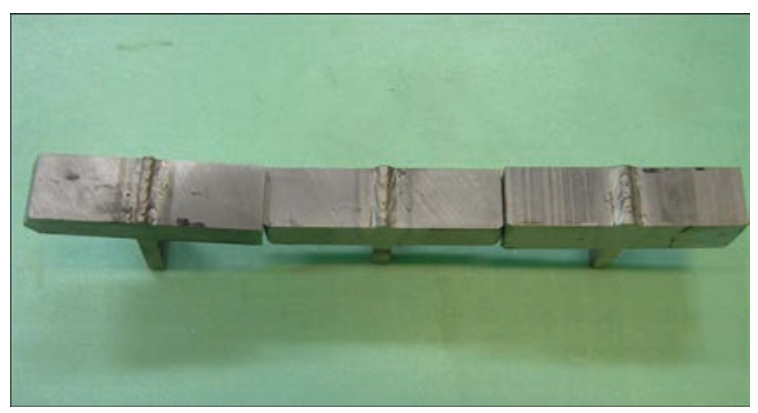

Figure 3. Appearance of EB-welded «disc-blade» T-joints of 12, 15 and $20 \mathrm{~mm}$ thickness

clude high-temperature brazing alloys VPr2, Vpr2M, PMFS 6-0.15 and powdered brazing alloys based on $\mathrm{Cr}, \mathrm{Ni}, \mathrm{Si}$ and $\mathrm{B}$. In the proposed technological scheme it was supposed to produce melting of brazing alloy and formation of fillets due to the heat from heating of metal during EBW.

Brazing alloy VPr2 (PM20ML) refers to the copper brazing alloys, providing high quality of brazed joints. The joints brazed with VPr2 have a significantly higher strength than those brazed with silver brazing alloys. These brazing alloys are not characterized by the ability to selective penetration along the grain boundaries of stainless steels and, therefore, can be applied for brazing of thin-walled structures. In non-aggressive environments the corrosion resistance of the joints brazed using these brazing alloys almost does not differ from the corrosion resistance of the joints brazed with silver brazing alloys.

Also, brazing alloy PMFS 6-0.15 alloyed with silicon or silicon and silver with decreased content of phosphorus has good properties. The limits of the alloying elements content in the brazing alloy are the following, wt.\%: $5-8 \mathrm{P} ; 0.1-1.5 \mathrm{Si}$; $\mathrm{Cu}$ is the rest. The brazing alloy of this composition is recommended for brazing of products of copper and brass operating without the exposure to significant impact loads. Melting point of brazing alloy is $725^{\circ} \mathrm{C}$, brazing temperature was $750-780^{\circ} \mathrm{C}$. For the products with an increased impact toughness of brazed joints the brazing alloy with the following composition was proposed, wt.\%: 5-6 P; $3 \mathrm{Ag}$; $0.15 \mathrm{Si}$; $\mathrm{Cu}$ is the rest; brazing temperature was $750-780{ }^{\circ} \mathrm{C}$.

To apply the brazing alloy into the blade-covering disc T-joint, the mixture based on acrylic resin BMK5 , powdered brazing alloy and solvent was prepared. This dough-like mixture was applied to the T-joint as is shown in Figure 5. After solidifying of the mixture in the air the specimens were loaded to the vacuum chamber and welding was performed at the already selected modes.

Unfortunately, this technological method did not give a positive result. Regardless of grade of brazing alloys a reliable formation of mating after EBW failed to be produced.

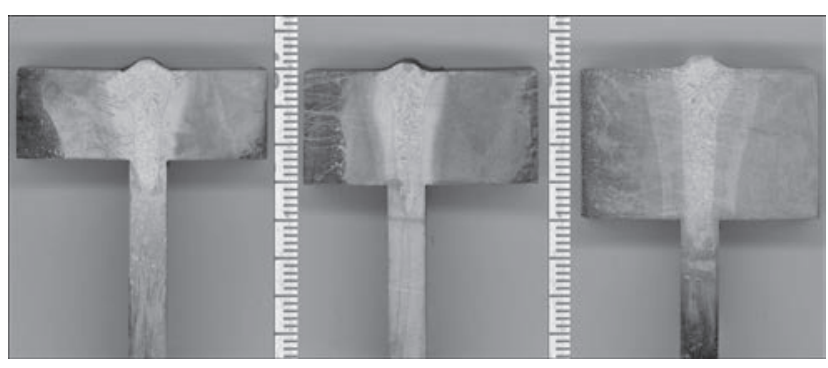

Figure 4. Cross sections of welds produced in EBW «disc-blade» joints of 12, 15 and $20 \mathrm{~mm}$ thickness

In the further developments the brazing alloys in the form of foil were applied:

- Cu-based brazing alloy $1.5 \mathrm{~mm}$ thick;

- brazing alloy based on brass $1.5 \mathrm{~mm}$ thick;

- steel brazing alloy without copper $1.5 \mathrm{~mm}$ thick;

- steel brazing alloy with low mixture of copper $1.5 \mathrm{~mm}$ thick;

- steel foil $0.1 \mathrm{~mm}$ thick;

- brass foil $0.1 \mathrm{~mm}$ thick.

For brazing alloys in the form of foil the scheme of assembly of welded joint was used shown in Figure 6. The upper edge of the blade was inserted into the milled groove on the covering disc of $1 \mathrm{~mm}$ depth. Between the walls of blade and the side surface of groove a gap was provided, into which the brazing alloy of a rectangular cross section was tightly laid. Thus, the width of groove was changed depending on the thickness of the applied brazing alloy.

The plates of brazing alloy, which were pressed into the groove, had a thickness from 0.1 to $1.5 \mathrm{~mm}$. After pressing and fixing the T-joint in the vacuum chamber, welding was performed according to the selected modes. But, as a result, none of the applied brazing alloys allowed obtaining the uniform formation of fillet between the blade and the disc. The best formation was obtained when applying brazing alloy based on brass and copper, however, the confident wetting of brazing alloy with the surface of the disc was also absent (Figure 7). The macrosection of welded joints with the copper brazing alloy is shown in Figure 8.

To provide a reliable formation of fillets the method of joining the blades with the covering disc with additional passes and melting of steel additives X3CrNiMo13-4 using electron beam was proposed. The scheme of the process is shown in Figure 9.

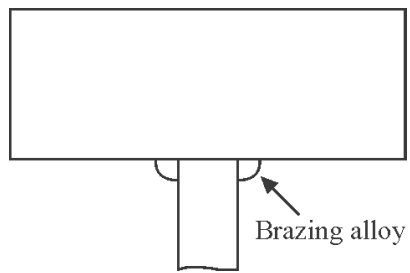

Figure 5. Scheme of brazing alloy embedding into T-joint 

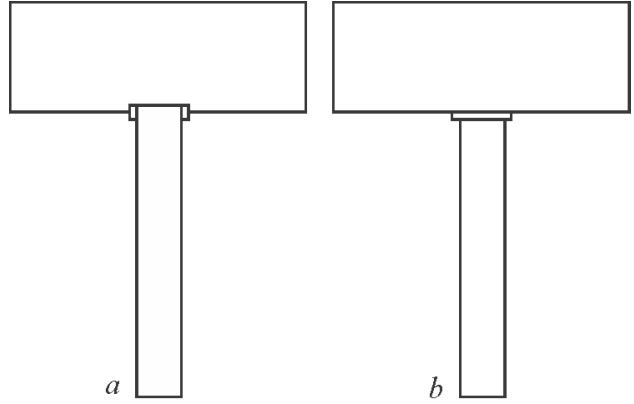

Figure 6. Scheme of embedding brazing alloy into «blade-covering disc» joint: $a$ - using groove in covering disc; $b$ - without groove

The additive was attached on the both sides of the blade (Figure 9) and EBW of the «disc-blade» joint was performed by vertical beam at the modes mentioned above. After that the specimen was turned over $90^{\circ}$ and fixed on the desktop. The EB gun was posi-
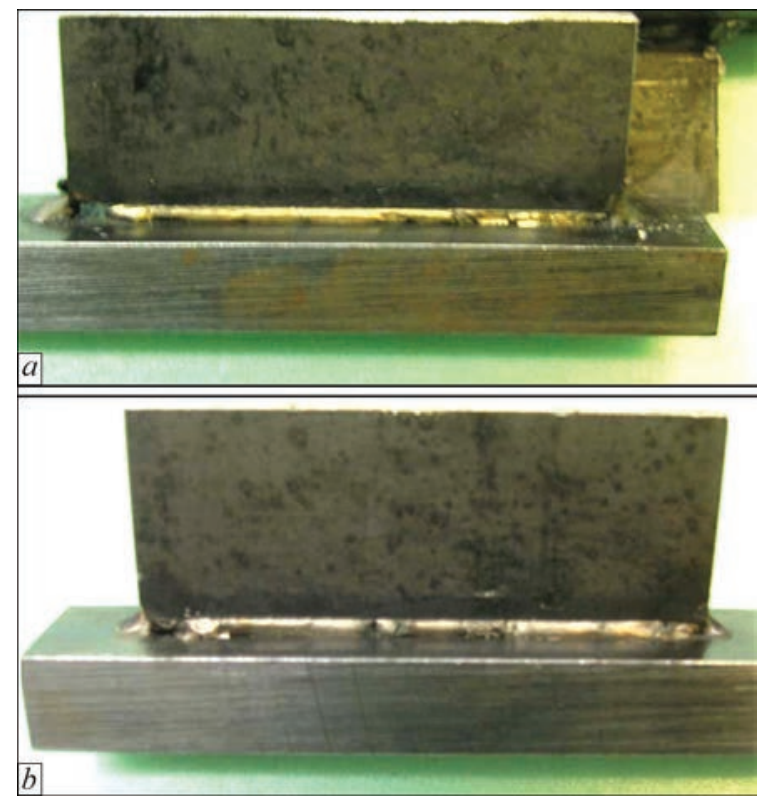

Figure 7. Formation of mating using brazing alloy based on brass (a) and copper (b)

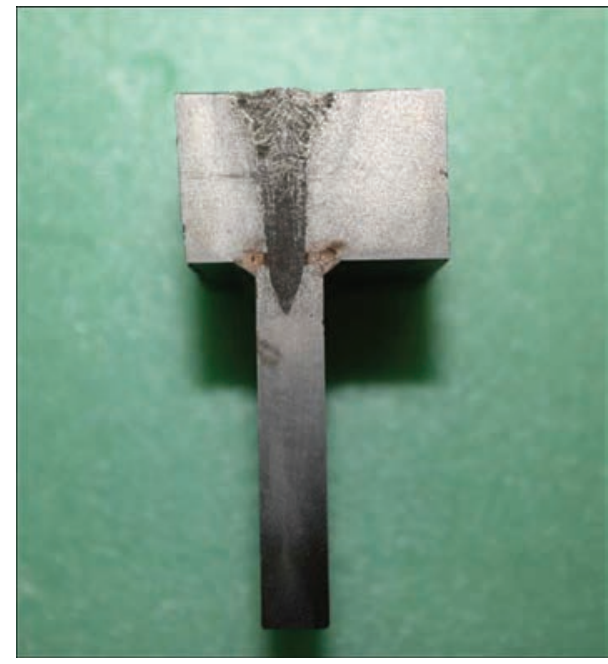

Figure 8. Macrosection of welded «blade-disc» joint produced using copper brazing alloy

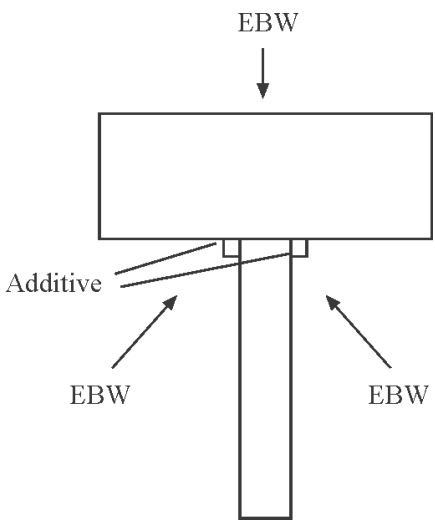

Figure 9. Scheme of welding «blade-disc» T-joint using electron beam for melting additive of steel X3CrNiMo13-4

tioned at angle of $5^{\circ}$ to the horizontal, allowing the beam to penetrate into the gap of the impeller for the whole length of the blade, to melt the additive and form a fillet. As a result a reliable weld and a perfect fillet formation of the «disc-blade» joint were produced (Figures 10 and 11).

The obtained results of EBW of models of the «blade-disc» joints of the impeller allowed us to design, manufacture and weld a model similar to real impellers produced at Company «Sumy Frunze NPO».

The gun fixed at a certain angle was moved along the coordinates $Z-Z$ and $Y-Y$. Simultaneously with the movement of the gun the rotation of the mockup was carried out using a precision rotator. Working out of the program of changing the coordinates of gun and mock-up movement in time was carried out using monitoring system RASTR- 6 . The uniformity of fillet formation between the disc and the blades is shown in Figure 12. The ultrasonic quality control of joints along the entire length of the blades did not reveal any deviations.

At the final stage of the investigations the impeller of centrifugal compressor of steel X3CrNiMo13-4 was prepared and welded (Figure 13). After the cleaning, assembly and coupling of the main and the covering discs the impeller was mounted on the rotator and

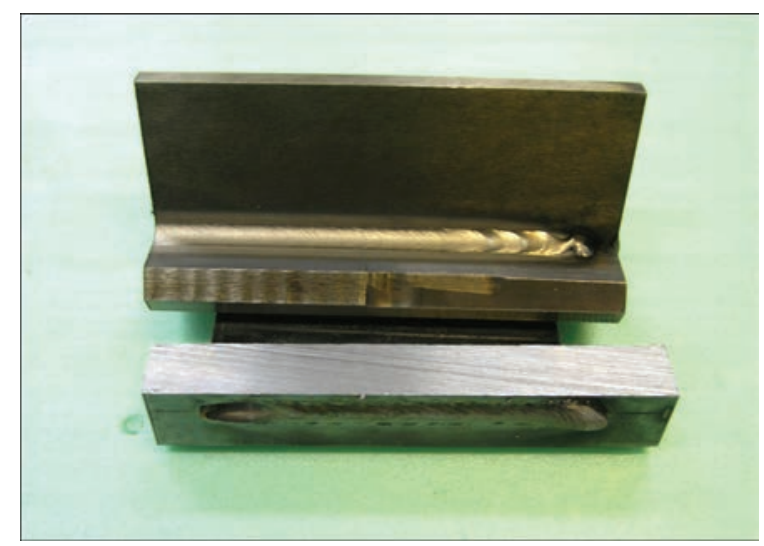

Figure 10. Formation of transition «blade-disc» joint during melting of additive with electron beam 


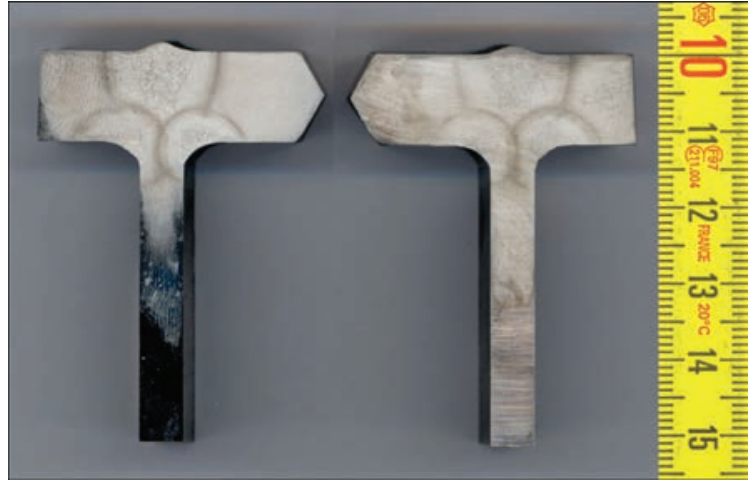

Figure 11. Macrosection of produced «blade-disc» joint

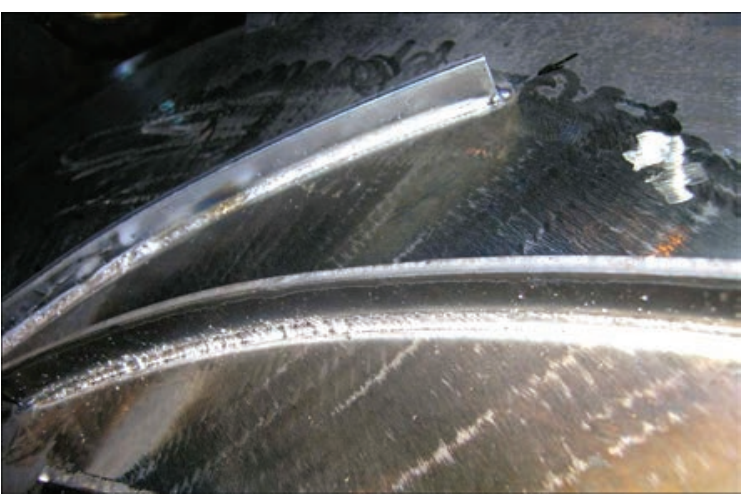

Figure 12. Formation of fillets on the impeller model

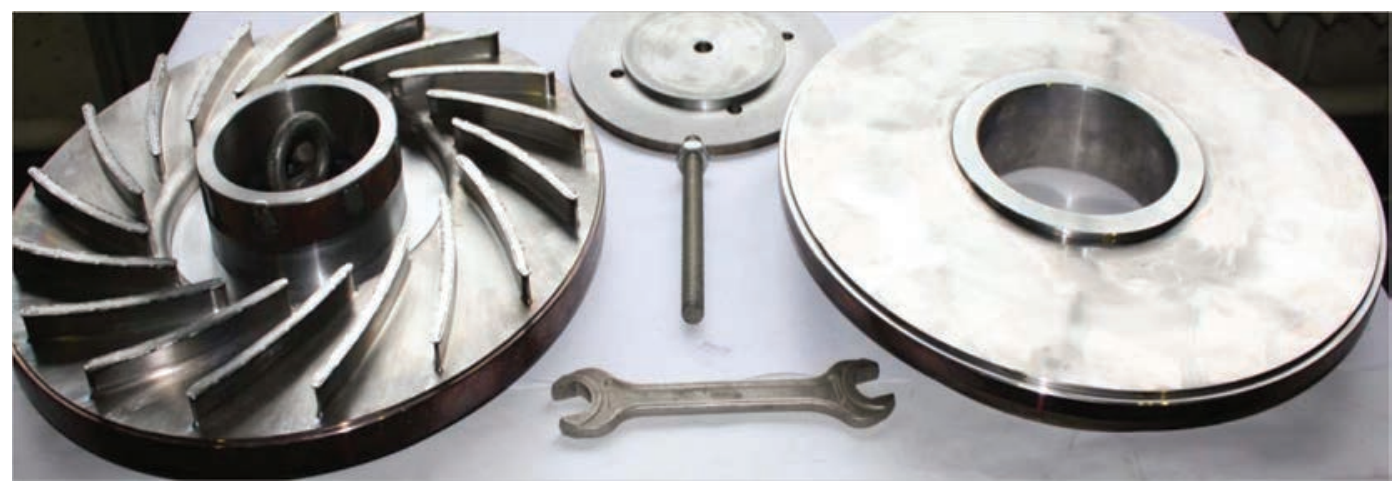

Figure 13. General view of main and covering discs of impeller before assembly and welding

placed into the vacuum chamber. Using the worked out technological process, the fillets were welded first on the side of convex part of the blades, and then on the side of aconcave one.

The movement of the gun was carried out along the two coordinates: $X-X$ and $Y-Y$, and the workpiece rotation during welding was provided by a high-precision rotator. EBW was carried out at the following mode: $U_{\text {acc }}=60 \mathrm{kV}$, bombardment current of $65 \mathrm{~mA}$, $L_{\mathrm{op}}=300 \mathrm{~mm}, I_{\mathrm{w}}=65 \mathrm{~mA}$, current of focusing lens of $615 \mathrm{~mA}$, and $v_{\mathrm{w}}=4 \mathrm{~mm} / \mathrm{s}$. General view of the welded impeller is presented in Figure 14.

After the final machining the impeller passed static and dynamic balancing with the subsequent acceleration tests at rotation speed of 11,295 rpm. After acceleration tests the reference sizes of the impeller were measured, which were preserved and equal to the corresponding sizes before the acceleration tests.

Thus, the possibility of manufacturing the centrifugal machine impellers was confirmed applying EBW, which provides the formation of fillets between the disc and the blades of $3 \mathrm{~mm}$ radius. The results of the work allow recommending the EBW technology for manufacture of standard impellers of the centrifugal machines.

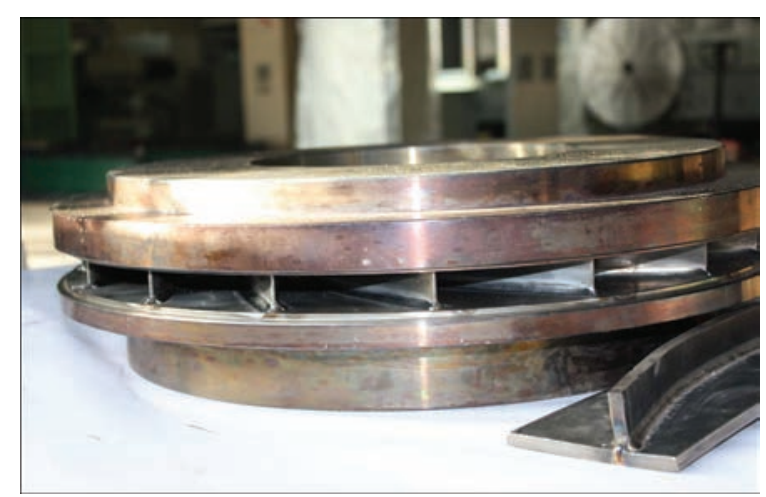

Figure 14. General view of welded impeller with fillets of $3 \mathrm{~mm}$ radius between blades and covering disc

1. Belousov, A.N., Musatkin, N.F., Radko, V.M. (2003) Theory and calculation of aircraft impeller machines. Samara: Samarsky Dom Pechati.

2. Laflamme, G., Rugh, J., MacWilliams, S. et al. (2006) Hybrid EBW process joins heavy-duty impellers. Welding J., 1, 44-47.

3. Myers, L., Laflamme, G. (2000) Electron beam braze welding of compressor impellers. The Paton Welding J., 8, 53-57.

4. C7.1M/C7.1:2004: Recommended practices for electron beam welding. Miami: AWS.

5. Radzievsky, V.N., Gartsunov, Yu.Yu., Tkachenko, G.G. et al. (2001) Specifics of formation of thick-wall T-joint using brazing and fusion welding. Svarochn. Proizvodstvo, 4, 42-46.

6. Radzievsky, V.N., Rymar, V.I., Bespalov, V.K. (1991) Vacuum brazing of T-joints with large fillet from metallic powder. Ibid., 8, 5-6.

Received 11.04.2016 